\title{
Significant changes in the bacterioplankton community structure of a maritime Antarctic freshwater lake following nutrient enrichment
}

Correspondence
David A. Pearce
dpearce@bas.ac.uk

Received 20 April 2004

Revised 14 July 2005

Accepted 18 July 2005

David A. Pearce, ${ }^{1}$ Christopher J. van der Gast, ${ }^{2}$ Kelly Woodward ${ }^{3} \dagger$ and Kevin K. Newsham ${ }^{1}$

\author{
${ }^{1}$ British Antarctic Survey, Natural Environment Research Council, High Cross, Madingley Road, \\ Cambridge CB3 OET, UK \\ ${ }^{2}$ Centre for Ecology and Hydrology, Mansfield Road, Oxford OX1 3SR, UK \\ ${ }^{3}$ Department of Molecular and Cell Biology, Institute of Medical Sciences, University of \\ Aberdeen, Foresterhill, Aberdeen AB25 2ZD, UK
}

\begin{abstract}
Nutrient enrichment is known to increase bacterioplankton population density in a variety of Antarctic freshwater lakes. However, relatively little is known about the associated changes in species composition. In this study, the bacterioplankton community composition of one such lake was studied following natural nutrient enrichment to investigate the resistance of the system to environmental change. Heywood Lake is an enriched freshwater maritime Antarctic lake, with nitrogen and phosphorus concentrations significantly higher than its more oligotrophic neighbours (by at least an order of magnitude). This major change in lake chemistry has occurred following large increases in the fur seal population over the last 30 years. Using analysis of $16 \mathrm{~S}$ rRNA gene fragments, fatty acid methyl ester analysis, denaturing gradient gel electrophoresis and fluorescence in situ hybridization, significant changes are reported in lake microbiology which have resulted in a distinct bacterioplankton community. In comparison to its more oligotrophic neighbours, nutrient-enriched Heywood Lake has a high bacterioplankton population density, reduced species richness and an increasing evenness among key groups. Only $42.3 \%$ of the clones found with $\geqslant 97 \%$ similarity to a named genus were also present in adjacent oligotrophic lakes, including three of the dominant groups. Critically, there was an apparent shift in dominance with trophic status (from the $\beta$-Proteobacteria to the Actinobacteria). Other key observations included the absence of a dominant group of Cyanobacteria and the presence of marine bacteria. The significant impact of natural nutrient enrichment on the microbiology of Heywood Lake, therefore, suggests that low-temperature oligotrophic freshwater lake systems might have low resistance to environmental change.
\end{abstract}

\section{INTRODUCTION}

There have been a number of investigations of nutrient enrichment in high latitude limnetic systems, which have demonstrated profound effects on the productivity and species composition of the phytoplankton (Bell \& Laybourn Parry, 1999; Unrein \& Vinocur, 1999; Izaguirre et al., 2001). In these studies, natural nutrient enrichment has resulted in significantly higher nitrate, phosphate and chlorophyll $a$ concentrations, higher bacterioplankton population densities, higher heterotrophic nanoflagellate and phototrophic

tPresent address: NCIMB Ltd, Ferguson Building, Craibstone Estate, Bucksburn, Aberdeen AB21 9YA, UK.

Abbreviations: DGGE, denaturing gradient gel electrophoresis; DRP, dissolved reactive phosphate; FAME, fatty acid methyl ester; FISH, fluorescence in situ hybridization; TDP, total dissolved phosphate. nanoflagellate abundances, dramatic shifts in species composition within the phytoplankton and high productivities creating seasonal anoxia under ice. In addition to these changes, Laybourn-Parry et al. (1996), Butler (1999a, b) and Butler et al. (2000) were able to show that significant changes in the protozooplankton community structure could occur over relatively short periods of time.

It is known from temperate and tropical areas that increased nutrient loading is often accompanied by a change in species composition (Hawes, 1990). Also, in polar environments, the character of freshwaters can be radically changed (e.g. switched from an oligotrophic to a eutrophic state), by quite minor events such as interference with an inflow or through the introduction of small amounts of inorganic or organic substances, especially if the volume is small (Fogg, 1998). Despite these observations, however, the community 
composition and taxonomy of the bacterioplankton has not been considered in detail, even though these communities are sensitive to disturbance and have been shown using fingerprinting techniques, to change with environmental conditions (Crump et al., 2003; Pearce, 2005). In lower latitude limnetic systems, differences in the bacterioplankton community composition between lakes of different trophic status have already been observed (Lindström, 2000), and it has been shown that the availability of nutrients and seasonal changes in nutrient concentrations can affect the bacterioplankton community composition (Donner et al., 1996; Yannarell et al., 2003). In this study, we examine the bacterioplankton community composition in Heywood Lake, Antarctica, and compare it to observed patterns in neighbouring Signy Island lakes with little (Sombre Lake) or no (Moss Lake) natural nutrient enrichment.

The significance of this particular system is that Heywood Lake is situated in a region of the globe subject to extremely rapid environmental change. Quayle et al. (2002) report data for the Signy Island lakes showing that mean lake temperatures in winter have increased by $0.9^{\circ} \mathrm{C}$ between 1980 and 1995, and nutrient levels at some sites exhibit order of magnitude increases per decade. In addition, photographic estimates suggest that permanent ice cover on these lakes has receded by approx. $45 \%$ since 1951, while lake ice records indicate that the open-water period has increased significantly. In this way, Heywood Lake might indicate the type of changes that could take place in analogous systems subjected to environmental change.

\section{METHODS}

Study site. Heywood Lake is situated in Three Lakes Valley on Signy Island in the South Orkney Islands $\left(60^{\circ} 43^{\prime} \mathrm{S}, 45^{\circ} 38^{\prime} \mathrm{W}\right)$, which lie at the northern extremity of the Maritime Antarctic. The island has the longest continuous record of biological research in Antarctica (Smith, 1997). It has been the subject of a number of investigations and is the main study site for long-term change. Glacial erosion has divided the island into six major catchments, in which there are 16 recognized lakes, representing all of the maritime Antarctic lacustrine environments. These small shallow lakes have formed following progressive deglaciation of Signy Island (Hawes, 1990). Most are oligotrophic (Heywood et al., 1980), but several are enriched and of these Heywood Lake is the best known and most extensively studied (Fig. 1a).

Heywood Lake itself is situated in a pre-glacial valley, it is the largest of the Signy Island Lakes and has been isolated from the ice cap for hundreds of years - moss fragments in basal sediments have been AMSradiocarbon dated to $5890 \pm 60{ }^{14} \mathrm{C}$ years BP (Jones et al., 2000). The lake is ice-covered to a maximum depth of $1 \mathrm{~m}$ for at least 8 months of the year, when the lake becomes anoxic and the water column clears. There are several small inflow streams, most notably from adjacent Knob Lake. The planktonic metazoan population of Heywood Lake consists of a few small crustaceans and rotifers (Butler, 1999a, b), but it contains no higher predators, such as fish or insect larvae, and lacks vascular and emergent plants.

Heywood Lake is $427 \mathrm{~m}$ long and $137 \mathrm{~m}$ wide with an area of $41730 \mathrm{~m}^{2}$. The lake comprises two basins separated by a shallow neck region. The larger north basin has a maximum depth of $6 \cdot 4 \mathrm{~m}$ and a
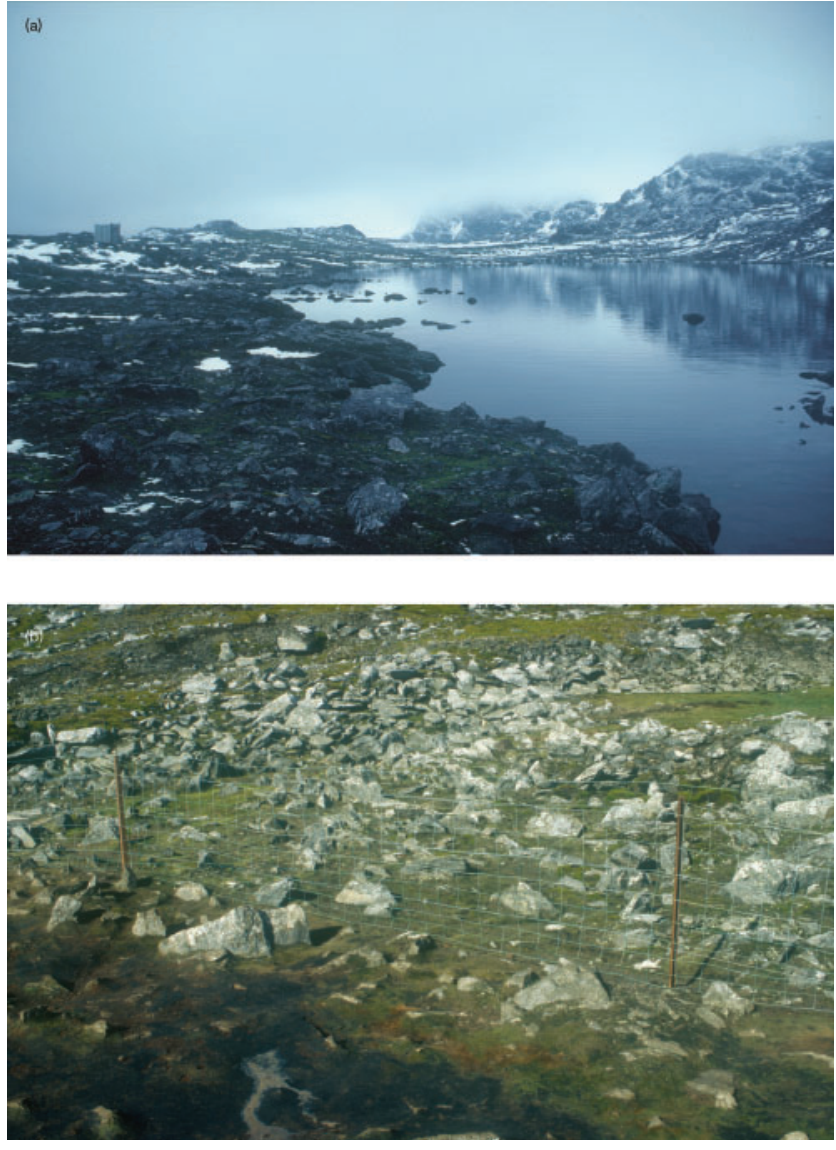

Fig. 1. (a) Heywood Lake, in Three Lakes Valley, on the north eastern side of Signy Island, in the South Orkney Islands, Antarctica $\left(60^{\circ} 43^{\prime} \mathrm{S}, 45^{\circ} 38^{\prime} \mathrm{W}\right)$. These islands lie at the northern extremity of the maritime Antarctic. (b) The dramatic impact of Antarctic fur seal populations on Signy Island moss communities, which has resulted in compaction and death of the indigenous moss flora and colonization by a nitrophilous alga characteristic of sites frequented by seals and birds. Note the seal exclusion fence installed to prevent further damage.

mean depth of $2 \mathrm{~m}$. Its drainage basin is composed of approximately $1 \%$ snow, $93 \%$ rock, $5 \%$ lichen and $1 \%$ moss cover, so the ice-free terrain is composed of frost-shattered rock and rudimentary soils formed from glacial diamiction (Noon et al., 2002). The lake lies only $4 \mathrm{~m}$ above sea level and is separated from the sea by $200 \mathrm{~m}$ of gently sloping ground. This permits ready access to the catchment by Antarctic fur seals (Arctocephalus gazella) and Southern elephant seals (Mirounga leonina). So Heywood Lake, although adjacent and physically similar to the oligotrophic Moss and Sombre Lakes, is different principally because its catchment is accessible to seals, which contribute considerable amounts of organic matter to the water. Unlike its more oligotrophic neighbours, there is evidence of high levels of nutrient input from seal activity over $33 \%$ of the catchment area, and up to $1 \%$ from bird activity, so that the total annual carbon gain in Moss Lake is less than an eighth of that in Heywood Lake (catchment data from Heywood et al., 1980; Ellis-Evans, 1982, 1990; and Fogg, 1998). Butler (1999a) obtained values of $0 \cdot 7-5 \cdot 1 \mathrm{mg}$ dissolved organic carbon $\mathrm{l}^{-1}$ and $0 \cdot 8-6 \cdot 4 \mathrm{mg}$ total organic carbon $\mathrm{l}^{-1}$ for Heywood Lake. A striking example of the impact on Signy Island moss communities is demonstrated by the presence of a seal exclusion fence (Fig. 1b). The 
once widespread moss carpet has been compacted and is now largely moribund; it has been recolonized by a community dominated by the nitrophilous alga Prasiola crispa, which is characteristic of sites frequented by seals and birds (Ellis-Evans, 1990).

Antarctic fur seal numbers in the Heywood Lake catchment area have increased markedly since 1974, and particularly since 1984, including a tenfold increase between 1976 and 1988 (see Fig. 2 and data in EllisEvans, 1990). Peak numbers (in February) have been monitored on Signy Island and have been found to increase from only a few animals each year in the 1950s and 1960s, to a few dozen in the early 1970s, but then to 2000-3000 between 1976 and 1983, 8000-17 000 between 1984 and 1993, 20500 in 1994 and 1995 (Smith, 1997) until, most recently, 10004 in 2003 (British Antarctic Survey, unpublished data). This expansion of the fur seal population has also been reported elsewhere in the Southern Ocean (Bester et al., 2003). The presence of the fur seals has resulted in considerable nutrient input, biological change and perturbation of the lake sediments, which are between 5000 and 7000 years old. Seal impact has been severe and both physical disturbance and nutrient toxicity have resulted in significant or complete destruction of Antarctic plant communities surrounding the lake. In addition to fur seal excrement and fur wash, plant and organic accumulations are being compressed and eroded into the lakes (Smith, 1997).

Sampling regime. Lake water samples were taken above the deepest point in Heywood Lake on 9 February 2000. Samples of 21 at each depth were taken over the following depth profile: at the surface (approx. $0.3 \mathrm{~m}$ ), from depths of 1,2, 3, 4 and $5 \mathrm{~m}$ and just above the bottom (approx. $5 \cdot 5 \mathrm{~m}$ ). Water samples were obtained from an inflatable boat using a hand-operated diaphragm pump and a rigid Durapipe tube of appropriate length. Samples were transported to the laboratory within $2 \mathrm{~h}$ in dark, acid-washed, pre-chilled Nalgene bottles, each rinsed three times with lake water from the appropriate sample depth before filling to overflowing.

Physical and chemical analyses. Vertical profiles of temperature, oxygen concentration and conductivity were taken at $1 \mathrm{~m}$ intervals with a Solomat WP4007 water quality meter connected to a 803PS Sonde (Zellweger Analytics). Light penetration was measured using a Grant 1000 series Squirrel logger connected to three SKP

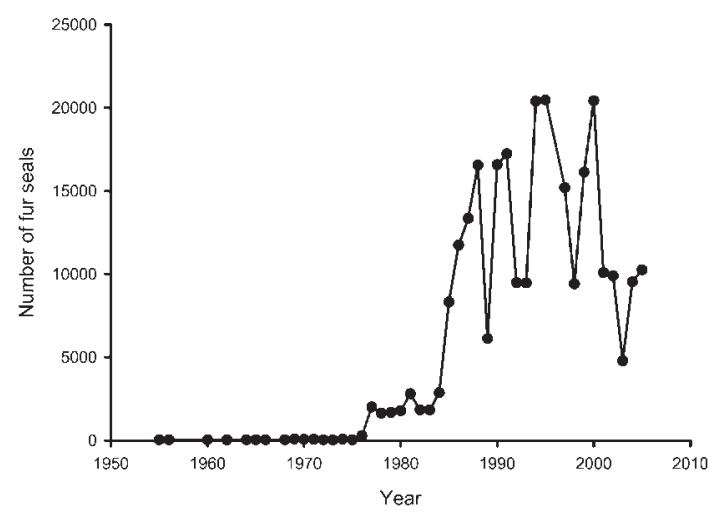

Fig. 2. Annual numbers of the Antarctic fur seal (Archtocephalus gazella) in February in the Heywood Lake catchment area, which have increased markedly since 1974, and particularly since 1984, including a tenfold increase between 1976 and 1988. The presence of the fur seals has resulted in considerable nutrient input, biological change and perturbation of the lake sediments.
215 flat quantum sensors (Skye Instruments). Subsamples of lake water $(500 \mathrm{ml})$ were filtered through Whatman GF/C filters using a Mityvac hand pump. Part of the $500 \mathrm{ml}$ subsamples were used for fluorometric analysis of chlorophyll $a$ concentrations, according to Welschmeyer (1994). Measurements of ammonium-N, nitrate-N, dissolved reactive phosphate (DRP), total dissolved phosphate (TDP) and chloride were measured using GF/C-filtered water and an Alpkem FS 3000 auto-analyser (Alpkem) with a model 5027 autosampler attached. Total dissolved nitrogen and dissolved reactive silicate were determined spectrophotometrically using the methods of D'Elia et al. (1977) and Mackereth et al. (1989), respectively. An Orion $250 \mathrm{~A} \mathrm{pH}$ meter was used to measure $\mathrm{pH}$ and alkalinity by the Gran titration technique (Mackereth et al., 1989).

Determination of total population density. The total population density in each sample was determined by direct microscopical counts of DAPI stained cells, using the method described by Porter \& Feig (1980).

Analysis of 16S rRNA gene fragments. Enzymic amplification of $16 \mathrm{~S}$ rDNA was performed on DNA extracted directly from Heywood Lake water using the method described by Pearce (2000). For these amplifications, each PCR mixture $(50 \mu \mathrm{l})$ contained $10 \mathrm{ng}$ extracted DNA as template, $10 \mathrm{pmol}$ each primer, $20 \mathrm{nmol}$ each dNTP, $1 \mathrm{U}$ SuperTaq polymerase (HT Biotech) and the SuperTaq buffer supplied with the enzyme. Primers used were 8F, 5'-AGAGTTTGATCCTGGCTCAG-3' (Dunbar et al. 1999), and 1500R, 5' -AGAAAGGAGGTGATCCAGCC-3' (Andrade et al. 2002), generating a $1492 \mathrm{bp}$ fragment. Amplification reactions were performed with a Genius thermocycler (Techne) using the following conditions: an initial denaturation step consisting of $94^{\circ} \mathrm{C}$ for 5 min, 30 cycles consisting of $94^{\circ} \mathrm{C}$ for $45 \mathrm{~s}, 55^{\circ} \mathrm{C}$ for $45 \mathrm{~s}, 72^{\circ} \mathrm{C}$ for $70 \mathrm{~s}$, and a final elongation step consisting of $72^{\circ} \mathrm{C}$ for $5 \mathrm{~min}$. Controls containing no DNA were also used to ensure that contaminants were not being amplified. The PCR products were cleaned using GFX PCR clean up columns (Pharmacia). Cleaned products were ligated into the pGEMT-Easy vector (Promega) and ligation mixtures were transformed into competent JM109 cells as recommended by the manufacturer. Transformants were screened using black/white selection on Luria agar containing S-Gal/IPTG and $50 \mu \mathrm{g}$ ampicillin $\mathrm{ml}^{-1}$ (Sigma). Putative positive colonies were transferred to individual tubes containing $50 \mu$ sterile water. The cell suspensions were subjected to two freeze/thaw cycles and $1 \mu \mathrm{l}$ aliquots were used as templates in a PCR reaction containing the M13F/M13R universal primers (M13F, 5'-CGCCAGGGTTTTCCCAGTCACGAC3'; M13R, 5'-GAGCGGATAACAATTTCACACAGG-3'). PCR conditions were as described above, except that the annealing temperature was raised to $58 \cdot 5^{\circ} \mathrm{C}$. A length $(760 \mathrm{bp})$ of each clone obtained was sequenced with the M13F primer using the Big Dye terminator kit v.2 (Applied Biosystems). Sequence reactions were carried out at the British Antarctic Survey using a Megabase 500 capillary sequencer. Clone sequences were compared with the GenBank nucleotide database using GAPPED-BLAST searches (http://www.ncbi.nlm.nih.gov/blast/ blast.cgi) (Altschul et al., 1997) to determine their closest phylogenetic neighbours. Identification to the genus level was defined as a $16 \mathrm{~S}$ rRNA gene sequence similarity of $\geqslant 97 \%$ with that of a sequence deposited in the EMBL database (Drancourt et al., 2000).

Direct culture of bacteria. Cultures were obtained by making a dilution series of lake water and pipetting $200 \mu \mathrm{l}$ onto solid caseinpeptone-starch (CPS), tryptic soy broth agar (TSBA) and R2A agar plates in three replicates. Plates were incubated at $4{ }^{\circ} \mathrm{C}$ for 2 months.

Fatty acid methyl ester (FAME) analysis. The phenotypic diversity and identity of individual strains isolated by direct culture was determined by FAME analysis, as described by Thompson et al. (1993) and van der Gast et al. (2001). The samples were injected into a Hewlett Packard model 5890 series II gas chromatograph. 
Fatty acid peaks were named by the Microbial Identification System (MIS) software (Microbial ID) and isolates were identified using the MIS 'Aerobe Library'.

Fluorescence in situ hybridization (FISH). A sample $(10 \mathrm{ml})$ of each lake-water sample was filtered through a black polycarbonate $0 \cdot 2 \mu \mathrm{m}$ screen membrane filter (Poretics). Cells were fixed with $2 \mathrm{ml}$ $4 \%$ paraformaldehyde in PBS for $30 \mathrm{~min}$. A gentle vacuum was then applied and cells were rinsed, initially in $5 \mathrm{ml} \mathrm{PBS}$, then in $5 \mathrm{ml}$ distilled water. Filters were removed from the filtration apparatus, air-dried, placed on a glass microscope slide and stored at $-20{ }^{\circ} \mathrm{C}$. Five different in situ hybridization probes were used specific for the domain Bacteria, the $\alpha-, \beta$ - and $\gamma$-subclasses of the Proteobacteria and the Cytophaga-Flavobacterium group as described by Pearce et al. (2003).

Denaturing gradient gel electrophoresis (DGGE). Enzymic amplification of $16 \mathrm{~S}$ rDNA was performed on extracted community DNA using the Muyzer primer pair (Muyzer et al., 1993) which amplifies corresponding Escherichia coli positions 341-534 bp of the $16 \mathrm{~S}$ rRNA gene. A volume of $25 \mu \mathrm{l}$ was separated by DGGE as described by Pearce (2000). The gel was run for $80 \mathrm{~min}$ at $60^{\circ} \mathrm{C}$ and $10 \mathrm{~V} \mathrm{~cm}^{-1}$, before staining for $45 \mathrm{~min}$ in a solution containing $0.5 \mu \mathrm{g}$ ethidium bromide $\mathrm{ml}^{-1}$. This was visualized on a UV transilluminator (UVP). Photographs were taken with a Gelcam (Polaroid) using Polaroid 665 professional positive/negative instant pack film. Gel images were analysed using Gelcompar II software (Applied Maths) and bands were determined using band recognition software. Bands were then excised, reamplified and cleaned using GFX PCR clean up columns (Pharmacia), ligated into the pGEMT-Easy vector (Promega) and transformed into competent JM109 cells as described for the rDNA clone libraries.

\section{RESULTS}

\section{Physical and chemical analyses}

Physical and chemical analyses showing the effects of nutrient enrichment, particularly on nitrogen and phosphorus concentrations, are given in Table 1 .

\section{Determination of total population density}

Total bacterioplankton population density in Heywood Lake ranged from a mean of $9.57 \times 10^{6}\left( \pm 1 \cdot 98 \times 10^{6}\right)$ DAPI stained cells $\mathrm{ml}^{-1}$ at $1 \mathrm{~m}$ to $1.5 \times 10^{7}\left( \pm 1 \cdot 0 \times 10^{6}\right)$ DAPI stained cells $\mathrm{ml}^{-1}$ at $3 \mathrm{~m}$.

\section{Direct 165 rDNA sequencing from environmental clones}

DNA from 60 environmental clones could be identified to within $\geqslant 97 \%$ of a named genus based on sequence comparison of $16 \mathrm{~S}$ rRNA genes. Using this information, $73.3 \%$ of the bacteria were affiliated with the $\beta$-Proteobacteria, $15 \cdot 0 \%$ with the $\alpha$-Proteobacteria and $11.8 \%$ with the Actinobacteria. The specific taxa found were the $\beta$-Proteobacteria genera Acidovorax, Alcaligenes, Bordetella, Janthinobacterium, Polaromonas, Polynucleobacter, Pseudomonas (mephitica), Rhodoferax and Variovorax, the $\alpha$-Proteobacteria genera Caulobacter, Rhodobacter and Sphingomonas, and the Actinobacteria taxa Aeromicrobium, Cryobacterium, Frigoribacterium and Actinomycetales (Table 2). Coverage was estimated to be $71 \cdot 7 \%$ (Good, 1953).

Table 1. Signy lake characteristics, physical and chemical analyses

All values are the mean over a depth profile during holomixis (13 January 2000) \pm SD. Abbreviation: PAR, photosynthetically active radiation.

\begin{tabular}{|c|c|c|c|}
\hline Character & Heywood & Sombre & Moss \\
\hline Reference & This study & Pearce et al. (2003) & Pearce (2003) \\
\hline Area (ha) & $4 \cdot 5$ & $2 \cdot 7$ & $1 \cdot 5$ \\
\hline Volume $\left(10^{-3} \times \mathrm{m}^{3}\right)$ & 96 & 133 & 52 \\
\hline Depth (m) & 6 & 11 & 10 \\
\hline Distance from the sea $(\mathrm{m})$ & 200 & 50 & 800 \\
\hline Height above sea level (m) & 4 & 10 & 48 \\
\hline Fur seal activity in the lake & High & Some & None \\
\hline Nitrate $\left(\mu \mathrm{g}^{-1}\right)$ & $1180 \pm 50$ & $185 \pm 7$ & $79 \pm 5$ \\
\hline Ammonium $\left(\mu \mathrm{g}^{-1}\right)$ & $161 \pm 6$ & $31 \pm 4$ & $38 \pm 2$ \\
\hline $\mathrm{DRP}\left(\mu \mathrm{g} \mathrm{l}^{-1}\right)$ & $124 \pm 5$ & $7 \pm 3$ & $8 \pm 2$ \\
\hline $\operatorname{TDP}\left(\mu \mathrm{g} 1^{-1}\right)$ & $157 \pm 19$ & $10 \pm 3$ & $15 \pm 8$ \\
\hline $\mathrm{pH}$ & $6 \cdot 5$ & $6 \cdot 7$ & $6 \cdot 1$ \\
\hline Alkalinity (meq $1^{-1}$ ) & $0 \cdot 1$ & $0 \cdot 2$ & $0 \cdot 1$ \\
\hline Chlorophyll $a\left(\mu \mathrm{g}^{-1}\right)$ & $7 \pm 1$ & $11 \pm 1$ & 2 \\
\hline Chloride $\left(\mathrm{mg} \mathrm{l}^{-1}\right)$ & $35 \pm 4$ & $34 \pm 9$ & $28 \pm 3$ \\
\hline Silicate $\left(\mu \mathrm{g} \mathrm{1^{-1 }}\right)$ & $167 \pm 2$ & $296 \pm 7$ & $118 \pm 2$ \\
\hline Temperature $\left({ }^{\circ} \mathrm{C}\right)$ & 4 & 3 & 2 \\
\hline Dissolved oxygen $\left(\mathrm{mg} \mathrm{l}^{-1}\right)$ & 3 & 13 & 13 \\
\hline Conductivity $\left(\mu \mathrm{S} \mathrm{cm}^{-1}\right)$ & 160 & 157 & 134 \\
\hline PAR (\% transmission) & 12 & 15 & 23 \\
\hline
\end{tabular}


Table 2. Heywood Lake clone $16 \mathrm{~S}$ rRNA gene sequences from extracted environmental DNA

Abbreviations: Lg, fragment length; Sm, similarity.

$\begin{array}{lcccc}\begin{array}{l}\text { Heywood Lake } \\ \text { clone accession no. }\end{array} & \begin{array}{c}\text { Heywood Lake clone closest } \\ \text { phylogenetic affiliation } \\ \text { following BLAST search } \\ \text { against the EMBL database }\end{array} & \begin{array}{c}\text { Accession no. } \\ \text { of BLAST } \\ \text { match }\end{array} & \begin{array}{c}\text { Sm } \\ \text { (bp) }\end{array} & \text { Class/phylum }\end{array}$

Heywood Lake clone
closest phylogenetic
affilation to a
named taxon

(a) Matches $\geqslant \mathbf{9 7} \%$ similarity

AJ878636 Unidentified eubacterium GKS16

AJ878625

AM049199

AM049186

AM049187

AM049188

AM049189

AM049190

AM049195

AM049192

AM049197

AM049193

AM049200

AM049284

AM049178

AM049229

AM049226

AM049227

AM049228

AM049230

AM049231

AM049232

AM049194

AJ878613

AM049179

AM049180

AM049181

AM049182

AM049185

AM049183

AJ878615

AM049184

AM049210

AM049211

AJ878633

AM049233

AM049201

AM049236

AM049225

AM049224

AM049234

AJ878624

AM049207

AJ878620

AM049217

AJ878617

AM049218

AM049215

AM049213
$\beta$-Proteobacterium Wuba72

$\beta$-Proteobacterium MWH-MoK4

$\beta$-Proteobacterium MWH-MoK4

$\beta$-Proteobacterium MWH-MoK4

$\beta$-Proteobacterium MWH-MoK4

$\beta$-Proteobacterium MWH-MoK4

$\beta$-Proteobacterium MWH-MoK4

$\beta$-Proteobacterium MWH-MoK4

$\beta$-Proteobacterium MWH-MoK4

Uncultured bacterium FukuS99

Uncultured bacterium FukuS99

Uncultured bacterium FukuN33

Polynucleobacter necessarius

Polynucleobacter necessarius

$\beta$-Proteobacterium HTCC528

$\beta$-Proteobacterium HTCC528

$\beta$-Proteobacterium HTCC528

$\beta$-Proteobacterium HTCC528

$\beta$-Proteobacterium HTCC528

$\beta$-Proteobacterium HTCC528

$\beta$-Proteobacterium HTCC528

Uncultured bacterium FukuS99

Polynucleobacter necessarius

Polynucleobacter necessarius

Polynucleobacter necessarius

Polynucleobacter necessarius

Polynucleobacter necessarius

Polynucleobacter necessarius

Polynucleobacter necessarius

Janthinobacterium lividum

Bordetella trematum DSM $11334^{(\mathrm{T})}$

Bordetella trematum

Unidentified eubacterium GKS98

Uncultured $\beta$-proteobacterium Elb24

Pseudomonas mephitica ATCC $33665^{\mathrm{T}}$

$\beta$-Proteobacterium MWH-MoK4

Janthinobacterium sp. HHS6

$\beta$-Proteobacterium HTCC528

Uncultured rape rhizosphere bacterium wr0041

Pseudomonas mephitica ATCC $33665^{\mathrm{T}}$

Pseudomonas mephitica ATCC $33665^{\mathrm{T}}$

Unidentified eubacterium GKS98

Unidentified eubacterium GKS98

Marine arctic deep-sea bacterium FD10

Marine arctic deep-sea bacterium FD10

Marine arctic deep-sea bacterium FD10

Antarctic bacterium R-8358

Antarctic bacterium R-8358

\begin{tabular}{|c|c|c|c|c|}
\hline AJ224987 & 688 & 99 & $\beta$-Proteobacteria & Variovorax \\
\hline AF336361 & 646 & 99 & $\beta$-Proteobacteria & Acidovorax \\
\hline AJ550654 & 685 & 99 & $\beta$-Proteobacteria & Polynucleobacter \\
\hline AJ550654 & 685 & 99 & $\beta$-Proteobacteria & Polynucleobacter \\
\hline AJ550654 & 685 & 99 & $\beta$-Proteobacteria & Polynucleobacter \\
\hline AJ550654 & 673 & 99 & $\beta$-Proteobacteria & Polynucleobacter \\
\hline AJ550654 & 677 & 99 & $\beta$-Proteobacteria & Polynucleobacter \\
\hline AJ550654 & 658 & 99 & $\beta$-Proteobacteria & Polynucleobacter \\
\hline AJ550654 & 667 & 99 & $\beta$-Proteobacteria & Polynucleobacter \\
\hline AJ550654 & 675 & 99 & $\beta$-Proteobacteria & Polynucleobacter \\
\hline AJ290020 & 673 & 99 & $\beta$-Proteobacteria & Polynucleobacter \\
\hline AJ290020 & 678 & 99 & $\beta$-Proteobacteria & Polynucleobacter \\
\hline AJ289997 & 673 & 99 & $\beta$-Proteobacteria & Polynucleobacter \\
\hline X93019 & 665 & 99 & $\beta$-Proteobacteria & Polynucleobacter \\
\hline X93019 & 666 & 99 & $\beta$-Proteobacteria & Polynucleobacter \\
\hline AY584576 & 657 & 99 & $\beta$-Proteobacteria & Polaromonas \\
\hline AY584576 & 662 & 98 & $\beta$-Proteobacteria & Polaromonas \\
\hline AY584576 & 678 & 98 & $\beta$-Proteobacteria & Polaromonas \\
\hline AY584576 & 689 & 98 & $\beta$-Proteobacteria & Polaromonas \\
\hline AY584576 & 673 & 98 & $\beta$-Proteobacteria & Polaromonas \\
\hline AY584576 & 685 & 98 & $\beta$-Proteobacteria & Polaromonas \\
\hline AY584576 & 683 & 98 & $\beta$-Proteobacteria & Polaromonas \\
\hline AJ290020 & 676 & 98 & $\beta$-Proteobacteria & Polynucleobacter \\
\hline X93019 & 681 & 98 & eobacteria & Polynucleobacter \\
\hline X93019 & 667 & 98 & $\beta$-Proteobacteria & Polynucleobacter \\
\hline X93019 & 684 & 98 & $\beta$-Proteobacteria & Polynucleobacter \\
\hline X93019 & 662 & 98 & $\beta$-Proteobacteria & Polynucleobacter \\
\hline X93019 & 684 & 98 & $\beta$-Proteobacteria & Polynucleobacter \\
\hline X93019 & 663 & 98 & $\beta$-Proteobacteria & Polynucleobacter \\
\hline X93019 & 686 & 98 & $\beta$-Proteobacteria & Polynucleobacter \\
\hline AF174648 & 747 & 98 & $\beta$-Proteobacteria & Janthinobacterium \\
\hline AJ277798 & 673 & 98 & $\beta$-Proteobacteria & Bordetella \\
\hline AJ27779 & 683 & 98 & $\beta$-Proteobacteria & Bordetella \\
\hline AJ224990 & 660 & 98 & $\beta$-Proteobacteria & Bordetella \\
\hline AJ421913 & 678 & 98 & $\beta$-Proteobacteria & Rhodoferax \\
\hline AB021388 & 744 & 98 & $\beta$-Proteobacteria & Pseudomonas \\
\hline AJ550654 & 643 & 97 & $\beta$-Proteobacteria & Polynucleobacter \\
\hline AJ846271 & 467 & 97 & $\beta$-Proteobacteria & Janthinobacterium \\
\hline AY584576 & 681 & 97 & $\beta$-Proteobacteria & Polaromonas \\
\hline AJ295499 & 785 & 97 & $\beta$-Proteobacteria & Polaromonas \\
\hline AB021388 & 795 & 97 & $\beta$-Proteobacteria & Pseudomonas \\
\hline AB021388 & 804 & 97 & $\beta$-Proteobacteria & Pseudomonas \\
\hline AJ224990 & 670 & 97 & $\beta$-Proteobacteria & Alcaligenes \\
\hline AJ224990 & 672 & 97 & $\beta$-Proteobacteria & Alcaligenes \\
\hline AJ557858 & 762 & 99 & $\alpha$-Proteobacteria & Sphingomonas \\
\hline AJ557858 & 751 & 98 & $\alpha$-Proteobacteria & Sphingomonas \\
\hline AJ557858 & 764 & 98 & $\alpha$-Proteobacteria & Sphingomonas \\
\hline AJ440993 & 786 & 98 & $\alpha$-Proteobacteria & Caulobacter \\
\hline AJ440993 & 778 & 98 & $\alpha$-Proteobacteria & Caulobacter \\
\hline
\end{tabular}


Table 2. cont.

\begin{tabular}{|c|c|c|c|c|c|c|}
\hline $\begin{array}{l}\text { Heywood Lake } \\
\text { clone accession no. }\end{array}$ & $\begin{array}{l}\text { Heywood Lake clone closest } \\
\text { phylogenetic affiliation } \\
\text { following BLAST search } \\
\text { against the EMBL database }\end{array}$ & $\begin{array}{c}\text { Accession no. } \\
\text { of BLAST } \\
\text { match }\end{array}$ & $\begin{array}{c}\mathrm{Lg} \\
(\mathrm{bp})\end{array}$ & $\begin{array}{l}\mathrm{Sm} \\
(\%)\end{array}$ & Class/phylum & $\begin{array}{l}\text { Heywood Lake clone } \\
\text { closest phylogenetic } \\
\text { affilation to a } \\
\text { named taxon }\end{array}$ \\
\hline AM049216 & Marine arctic deep-sea bacterium FD10 & AJ557858 & 814 & 97 & $\alpha$-Proteobacteria & Sphingomonas \\
\hline AJ878623 & Caulobacter sp. CB66 & AJ227788 & 813 & 97 & $\alpha$-Proteobacteria & Caulobacter \\
\hline AM049212 & Uncultured rape rhizosphere bacterium wr0066 & AJ295562 & 725 & 97 & $\alpha$-Proteobacteria & Caulobacter \\
\hline AJ878632 & Aquatic bacterium R1-A7 & AB195725 & 678 & 97 & $\alpha$-Proteobacteria & Rhodobacter \\
\hline AJ878614 & Aeromicrobium marinum & AY166703 & 774 & 97 & Actinobacteria & Aeromicrobium \\
\hline AM049204 & Aeromicrobium marinum & AY166703 & 792 & 98 & Actinobacteria & Aeromicrobium \\
\hline AM049205 & Aeromicrobium marinum & AY166703 & 791 & 98 & Actinobacteria & Aeromicrobium \\
\hline AM049202 & Aeromicrobium marinum & AY166703 & 813 & 97 & Actinobacteria & Aeromicrobium \\
\hline AJ878618 & Actinomycetales & AY145533 & 688 & 97 & Actinobacteria & Actinomycetales \\
\hline AJ878627 & Cryobacterium psychrophilum & AJ297438 & 770 & 97 & Actinobacteria & Cryobacterium \\
\hline AJ878631 & Antarctic bacterium R-9112 & AJ441003 & 787 & 97 & Actinobacteria & Frigoribacterium \\
\hline \multicolumn{7}{|c|}{ (b) Matches $<97 \%$ similarity } \\
\hline AM049238 & Unidentified $\beta$-Proteobacterium HTC018 & AB010865 & 491 & 96 & $\beta$-Proteobacteria & Janthinobacterium \\
\hline AM049221 & Uncultured rape rhizosphere bacterium wr0041 & AJ295499 & 762 & 96 & $\beta$-Proteobacteria & Polaromonas \\
\hline AM049223 & Uncultured rape rhizosphere bacterium wr0041 & AJ295499 & 811 & 96 & $\beta$-Proteobacteria & Polaromonas \\
\hline AM049209 & Bordetella trematum DSM $11334^{(\mathrm{T})}$ & AJ277798 & 681 & 96 & $\beta$-Proteobacteria & Bordetella \\
\hline AM049222 & Unidentified eubacterium GKS16 & AJ224987 & 809 & 96 & $\beta$-Proteobacteria & Polaromonas \\
\hline AM049206 & Uncultured bacterium FukuS93 & AJ290018 & 675 & 96 & $\beta$-Proteobacteria & Alcaligenes \\
\hline AM049191 & $\beta$-Proteobacterium MWH-MoK4 & AJ550654 & 693 & 96 & $\beta$-Proteobacteria & Polynucleobacter \\
\hline AM049208 & Uncultured bacterium FukuN65 & AJ290001 & 389 & 96 & $\beta$-Proteobacteria & Alcaligenes \\
\hline AM049239 & Pseudomonas mephitica ATCC $33665^{\mathrm{T}}$ & AB021388 & 795 & 96 & $\beta$-Proteobacteria & Pseudomonas \\
\hline AJ878622 & Uncultured bacterium FukuS93 & AJ290018 & 674 & 95 & $\beta$-Proteobacteria & Achromobacter \\
\hline AM049237 & Janthinobacterium sp. HHS6 & AJ846271 & 622 & 95 & $\beta$-Proteobacteria & Janthinobacterium \\
\hline AM049235 & Janthinobacterium sp. J43 & AJ864852 & 495 & 94 & $\beta$-Proteobacteria & Janthinobacterium \\
\hline AM049198 & Uncultured bacterium FukuN33 & AJ289997 & 678 & 93 & $\beta$-Proteobacteria & Polynucleobacter \\
\hline AM049196 & Uncultured bacterium FukuN33 & AJ289997 & 676 & 93 & $\beta$-Proteobacteria & Polynucleobacter \\
\hline AM049220 & Sphingobium yanoikuyae & AB120764 & 464 & 96 & $\alpha$-Proteobacteria & Sphingobium \\
\hline AJ878626 & Afipia massiliensis & AY029562 & 676 & 95 & $\alpha$-Proteobacteria & Afipia \\
\hline AM049214 & Caulobacter sp. CB66 & AJ227788 & 456 & 95 & $\alpha$-Proteobacteria & Caulobacter \\
\hline AM049219 & Sphingomonas sp. EVA17 & AY212804 & 541 & 94 & $\alpha$-Proteobacteria & Sphingomonas \\
\hline AJ878634 & Sphingopyxis macrogoltabida HXN-200 & AJ784806 & 151 & 88 & $\alpha$-Proteobacteria & Sphingopyxis \\
\hline AM049203 & Aeromicrobium marinum & AY166703 & 730 & 96 & Actinobacteria & Aeromicrobium \\
\hline AM049241 & Actinomycetales bacterium GP-5 & AY145533 & 681 & 96 & Actinobacteria & Actinomycetales \\
\hline AJ878619 & Unidentified bacterium rJ14 & $\mathrm{AB} 021332$ & 676 & 94 & Actinobacteria & Actinoplanes \\
\hline AM049240 & Unidentified bacterium rJ7 & AB021325 & 659 & 92 & Actinobacteria & Actinomycetales \\
\hline AJ878635 & Unidentified bacterium rJ7 & AB021325 & 519 & 89 & Actinobacteria & Sporichthya \\
\hline AJ878630 & Frankia sp. HR27-14 & L40617 & 525 & 87 & Actinobacteria & Frankia \\
\hline AJ878629 & Flavobacterium xinjiangense As1.2748 & AF433172 & 182 & 95 & Bacteroidetes & Flavobacterium \\
\hline AJ878628 & Flavobacterium sp. R-21935 & AJ786797 & 470 & 77 & Bacteroidetes & Flavobacterium \\
\hline AJ878637 & Uncultured bacterium FukuN18 & AJ289992 & 658 & 91 & Verrucomicrobia & Verrucomicrobium \\
\hline
\end{tabular}

\section{FAME analysis}

Using FAME analysis, $82 \cdot 7 \%$ of bacteria were identified as Actinobacteria, $6.9 \%$ as Firmicutes, $6.9 \%$ as $\gamma$-Proteobacteria and $3.4 \%$ as $\alpha$-Proteobacteria. The specific genera found were the Actinobacteria genera Arcanobacterium, Cellulomonas, Micrococcus, Rhodococcus and Tsukamurella, the Firmicutes genus Staphylococcus, the $\gamma$-Proteobacteria genera Acinetobacter and Stenotrophomonas and the $\alpha$-Proteobacteria genus Sphingomonas. Perhaps surprisingly, given their overall dominance in freshwaters, the $\beta$-Proteobacteria were not identified in Heywood Lake samples using FAME analysis. Isolation frequencies are given in Fig. 3.

\section{FISH}

With a set of four probes for the major divisions within the domain Bacteria, it was possible to affiliate between $47 \cdot 7$ and 


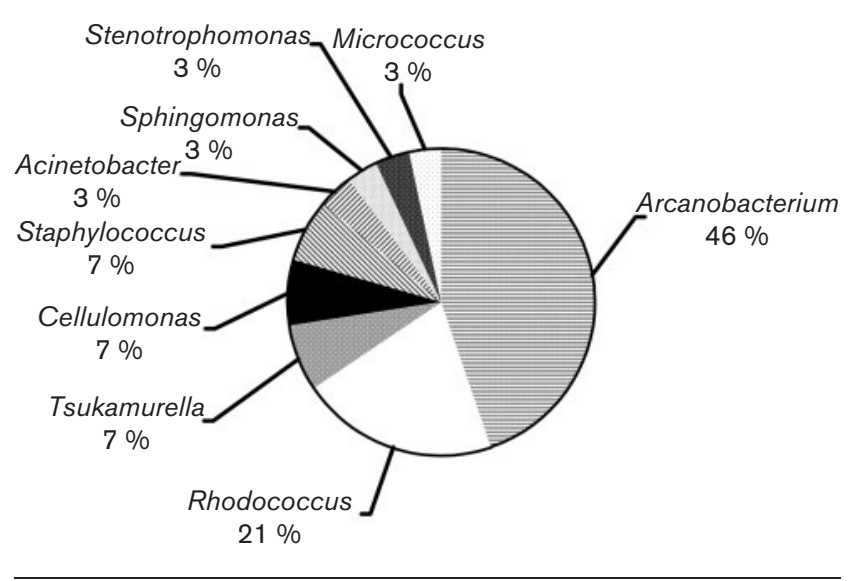

Fig. 3. Isolation frequency of different genera by FAME analyses of cultured strains isolated from Heywood Lake.

$64.5 \%$ of the EUB338-hybridized cells with known bacterial groups. With the exception of the $3 \mathrm{~m}$ sample, the $\beta$ Proteobacteria was clearly the most abundant group at all depths sampled and the $\alpha$-Proteobacteria was the least abundant group at most depths studied (Fig. 4).

\section{DGGE}

DGGE analysis of Heywood Lake water at vertical depth intervals produced 13 distinct DGGE bands, with the exception of the bottom level water which may have included some sediment, suggesting the presence of up to 13 potentially dominant bacterioplankton groups (Fig. 5). The clones derived from DGGE products were dominated by operational taxonomic units belonging to uncultured bacteria, including representatives of the Actinobacteria (53.8\%), the Bacteroidetes $(23 \cdot 1 \%)$, the Gram-positives $(15 \cdot 4 \%)$ and the $\beta$-Proteobacteria $(7 \cdot 7 \%)$. The specific clones identified were the actinobacterium MWH-VicMual and six uncultured

\begin{tabular}{ccc} 
Profiles & \multicolumn{3}{c}{ Depth } \\
& & \\
& &
\end{tabular}

Gel running direction $\Rightarrow$

Fig. 5. DGGE profile of Heywood Lake during a period of holomixis. The DGGE image was captured as a TIFF file, which was then analysed with Gelcompar II (Applied Maths). All clear DGGE bands, representing either individual DNA fragments or groups of DNA fragments, were scored independently when recognized by the band recognition search in Gelcompar II. Abbreviations: D4, 9 February 2000; H, Heywood Lake; SF, surface sample; B, bottom sample. All numbers refer to the depth at which the respective sample was taken. H3 samples were excised for sequencing.

actinobacterium clones, including CL500-95, FBP402, TLM06, CLO-29, c270 and an unidentified clone. Within the Bacteroidetes-specific clones were Flavobacterium xinjiangense and an unidentified Cytophagales sp.; within the $\beta$-Proteobacteria was Pelistega europaea, and within the Gram-positives were uncultured GOBB3-CL171 and Z39. Significantly, a clone from Moss Lake DGGE band 1 (UBA520090) was also identified (Table 3).

\section{DISCUSSION}

\section{Nutrient enrichment and bacterioplankton population density}

Nutrient concentrations in Heywood Lake were significantly higher than in neighbouring oligotrophic Moss and Sombre

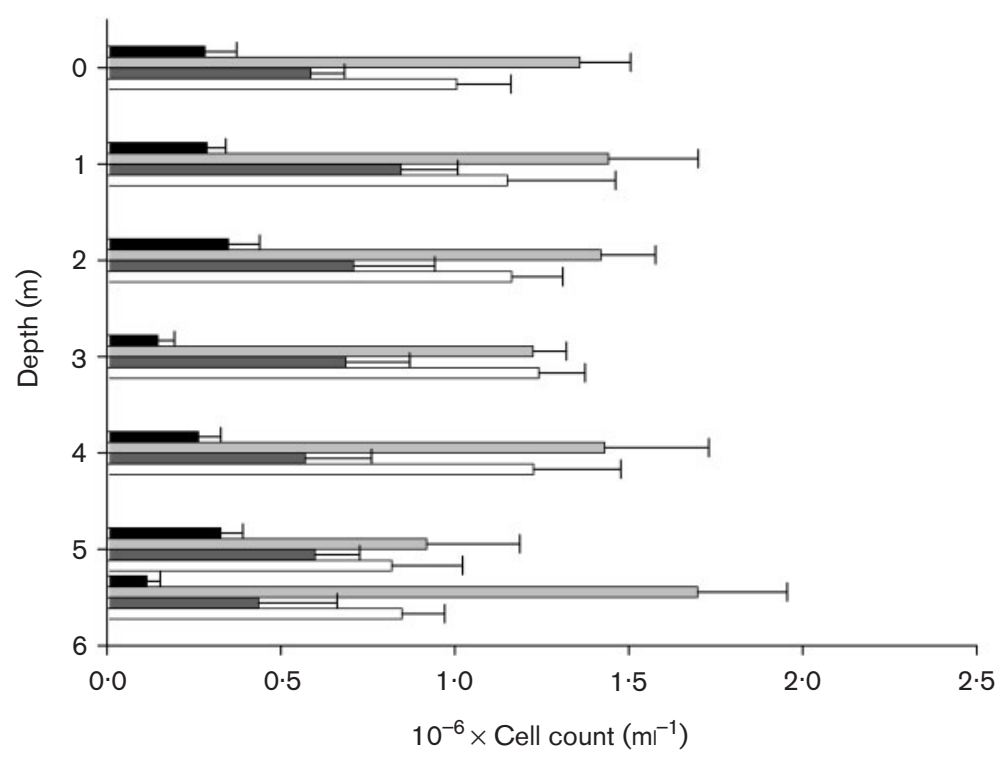

Fig. 4. Distribution of key bacterioplankton groups in Heywood Lake with depth, as determined by FISH. Error bars represent SD $(n=10)$. Black bars, $\alpha$-Proteobacteria; light grey bars, $\beta$-Proteobacteria; dark grey bars, $\gamma$-Proteobacteria; white bars, CytophagaFlavobacterium group. 
Table 3. Identification of cloned and sequenced DGGE bands from a depth of $3 \mathrm{~m}$ in Heywood Lake

Abbreviations: Lg, fragment length; Sm, similarity; Uncl., unclassified.

\begin{tabular}{|c|c|c|c|c|c|c|c|}
\hline $\begin{array}{l}\text { DGGE band } \\
\text { sequence } \\
\text { accession no. }\end{array}$ & $\begin{array}{c}\text { Moss Lake DGGE } \\
\text { band closest } \\
\text { phylogenetic affiliation }\end{array}$ & $\begin{array}{l}\text { Accession } \\
\text { no. }\end{array}$ & $\begin{array}{c}\mathrm{Lg} \\
(\mathrm{bp})\end{array}$ & $\begin{array}{l}\text { Sm } \\
(\%)\end{array}$ & Class/phylum & $\begin{array}{c}\text { Closest phylogenetic } \\
\text { affiliation with a } \\
\text { named taxon }\end{array}$ & $\begin{array}{c}\text { Source } \\
\text { of matches }\end{array}$ \\
\hline AJ865590 & Actinobacterium MWH-VicMual & AJ565417 & 156 & 98 & Actinobacteria & Microbacterium sp. & Freshwater \\
\hline AJ865591 & Flavobacterium xinjiangense & AF433172 & 190 & 99 & Bacteroidetes & Flavobacterium sp. & Glacier \\
\hline AJ865592 & Uncultured bacterium CL500-95 & AF316665 & 158 & 99 & Actinobacteria & Actinomycete & Crater lake \\
\hline AJ865593 & Pelistega europaea & UE16SRR & 113 & 91 & $\beta$-Proteobacteria & Neisseria sp. & Avian pathogen \\
\hline AJ865594 & $\begin{array}{l}\text { Uncultured actinobacterium clone } \\
\text { FBP } 402\end{array}$ & AY250880 & 170 & 94 & Actinobacteria & Micrococcineae sp. & Antarctic \\
\hline AJ865595 & $\begin{array}{l}\text { Uncultured actinobacterium clone } \\
\text { TLM06 }\end{array}$ & AF534430 & 175 & 99 & Actinobacteria & Kineococcus-like sp. & Arctic lake \\
\hline AJ865596 & Uncultured actinobacterium & AY562361 & 123 & 100 & Actinobacteria & Tetrasphaera sp. & Delaware river \\
\hline AJ865597 & Uncultured bacterium CL0-29 & AF316680 & 102 & 98 & Actinobacteria & Rhodococcus sp. & Crater lake \\
\hline AJ865598 & Uncultured bacterium clone c270 & AY154621 & 157 & 98 & Actinobacteria & Kineococcus-like sp. & Earthworm cast \\
\hline AJ865599 & Uncultured firmicute GOBB3-CL171 & AF388895 & 164 & 96 & Uncl. Gram + ve & Actinomycete & Estuary \\
\hline AJ865600 & Moss Lake DGGE band 1 & UBA520090 & 169 & 100 & Bacteroidetes & Flavobacterium sp. & Adjacent lake \\
\hline AJ865601 & Uncultured bacterium clone Z39 & AF488674 & 107 & 96 & Uncl. Gram + ve & Tetrasphaera sp. & Freshwater \\
\hline AJ865602 & Unidentified cytophagales bacterium & AJ007870 & 121 & 91 & Bacteroidetes & Cytophaga sp. & Swedish lake \\
\hline
\end{tabular}

Lakes. In particular, there were large differences in the concentrations of nitrogen and phosphorus (Table 1). Heywood Lake supported a higher bacterioplankton population density, with between 50- and 15-times the population densities in Moss and Sombre lakes, respectively.

\section{Similarities with adjacent oligotrophic lakes}

Overall, the bacterioplankton community in Heywood Lake was dominated by genera with characteristics that included the ability to utilize a wide variety of organic compounds and involvement in the mineralization of organic matter, they were all aerobic (or facultatively anaerobic), they contained species which produced pigment and were widely distributed globally in fresh waters. All of these properties are normally associated with oligotrophic aerobic pelagic environments (Pearce, 2003; Pearce et al., 2003). The genera identified in Heywood Lake through 16S rDNA sequencing or FAME analysis that were also present in oligotrophic Sombre Lake (Pearce et al., 2003) were Acidovorax, Arcanobacterium, Bordetella, Cellulomonas, Flavobacterium, Janthinobacterium, Micrococcus, Pseudomonas, Rhodobacter, Sphingomonas and Staphylococcus. This represents a Sørensen coefficient of $0 \cdot 20$, or $42 \cdot 3 \%$ of the genera identified in this study.

\section{Differences from adjacent oligotrophic lakes}

Bacterioplankton taxa identified in nutrient-enriched Heywood Lake from direct $16 \mathrm{~S}$ rDNA sequencing or FAME analysis included: Acinetobacter, Actinobacteria, Actinomycetales, Aeromicrobium, Caulobacter, Cryobacterium, Frigoribacterium, Pelistega, Polaromonas, Polynucleobacter, Rhodococcus, Rhodoferax, Stenotrophomonas, Tsukamurella and Variovorax. These groups were not found in the neighbouring oligotrophic lakes.

Heywood Lake bacterioplankton was dominated by bacteria most of which have yet to be cultivated (Table 3). Of the 13 dominant groups identified using DGGE, eight were closely related to uncultivated bacteria in the database, three were identified to genus level and only two could be identified to species level. This pattern is consistent with oligotrophic Moss and Sombre Lakes, and at least three of the dominant groups in Heywood Lake were identical to dominant groups in the oligotrophic systems. However, in nutrient-enriched Heywood Lake, there was a larger number of dominant groups: Moss Lake 9, Sombre Lake 8 and Heywood Lake 13.

\section{Cyanobacteria}

DGGE suggested the importance of the Actinobacteria and, unlike both of the oligotrophic lakes used for comparison, none of the dominant bacterioplankton were Cyanobacteria. This is unusual, as many of the microbial communities in non-marine ecosystems within polar regions are dominated by Cyanobacteria, with populations that are amongst the highest recorded in any natural environment (Vincent et al., 2000). This observation is supported by the dominance (as determined by DGGE) of Nostoc sp. in Moss Lake (Pearce, 2003) and an uncultured cyanobacterium clone in Sombre Lake (Pearce et al., 2003). The lack of cyanobacterial dominance might be linked to the high nitrogen concentration associated with fur seal enrichment, as relatively high $\mathrm{N}: \mathrm{P}$ ratios in nutrient-rich lakes tend to favour noncyanobacterial taxa (Smith, 1983, 1990). This might also be due to the observation that pico-cyanobacteria have a high nutrient-scavenging ability and can be an important part of the pelagic community in terms of biomass in more 
oligotrophic conditions (Stockner, 1988; Stockner et al., 2000).

\section{Marine species}

A particularly interesting feature of the Heywood Lake bacterioplankton was the presence of psychrophilic marine bacteria, including Polaromonas vacuolata (Irgens et al., 1996) and Rhodobacter sphaeroides (Pinhassi et al., 1997). In addition, the $\alpha$-Proteobacteria were significant and, though not exclusively, are more traditionally associated with marine environments. This is probably due to the close proximity of the lake to the sea and frequent visits by marine mammals and birds. Although we cannot be certain that the marine bacteria were active within the lake, the relatively high levels of $\alpha$-Proteobacteria, as determined by FISH, suggested that they might be (as the probes target rRNA). A similar phenomenon was observed by Bell \& LaybournParry (1999) in nutrient-enriched Rookery Lake, where the ciliate community resembled the marine community and was dissimilar to that found in older saline lakes within the Vesthold Hills.

\section{Ubiquity of bacterioplankton genera}

Although the Heywood Lake bacterioplankton community was not consistent with neighbouring oligotrophic lakes, many of the genera isolated from Heywood Lake represented ubiquitous aquatic bacteria and the bacteria most common in aquatic habitats, such as Gram-negative rods, particularly Pseudomonas and Flavobacterium. In addition, surface films formed during calm weather on lakes and ponds often comprise Pseudomonas, Caulobacter, Flavobacterium and Micrococcus. Significantly, many of the genera found have been identified in freshwater systems elsewhere (Table 4), including nutrient-enriched systems in temperate areas such as soil, marine, alkaline, sedimentary and estuarine systems, and as such it might be more appropriate, as suggested by Reynolds et al. (2002) for the phytoplankton and by Yannarell et al. (2003) for the bacterioplankton, to develop and use a functional classification of these aquatic micro-organisms.

Specific examples of the common occurrence of key genera identified in Heywood Lake are Flavobacterium xinjiangense and members of the Actinobacteria. Flavobacterium xinjiangense, widely distributed in fresh and marine waters (Zhu et al., 2003) was also found in both Moss Lake (Pearce, 2003) and Sombre Lake (Pearce et al., 2003). The Flavobacteria show a high abundance in aquatic ecosystems and these heterotrophic bacteria may have a specialized role in uptake and degradation of the high-molecular-mass fraction of dissolved organic matter in these environments (Kirchman, 2002). In addition, the predominant group, the uncultured Actinobacteria, have been described in freshwater habitats in Europe and Asia (Hahn, 2003). The ecological implications of this observation are that freshwater ecosystems contain similar bacterioplankton at the genus level, but that at the
Table 4. A comparison of taxa identified in Heywood Lake, by FAME, DGGE and 16S rRNA gene sequence analysis (where clones have $\geqslant 97 \%$ similarity with the named taxon) to lake systems elsewhere

Abbreviations: s, Sombre Lake, Signy Island (Pearce et al., 2003); a, Adirondack Mountain lakes (Hiorns et al., 1997); b, Lake Baikal (Korsunov et al., 2003); g, oligotrophic high mountain Lake Gossenköllesee, mesotrophic Lake Fuchskuhle and Lake Baikal (Glöckner et al., 2000); 1, Bugach and Lesnoi turbid Siberian ponds (Trusova \& Gladyshev, 2002); o, oligotrophic crater lake, Oregon, USA (Urbach et al., 2001); p, eutrophic priest pot (Finlay \& Maberly, 2000); z, typical freshwater bacteria (Zwart et al., 2002).

\begin{tabular}{|c|c|c|c|c|c|c|c|c|}
\hline Taxon & $\mathbf{s}$ & $\mathbf{a}$ & b & $\mathbf{g}$ & 1 & $\mathbf{o}$ & $\mathbf{p}$ & $\mathbf{z}$ \\
\hline Acidovorax & $\mathbf{\square}$ & & & & $\square$ & & & \\
\hline Acinetobacter & & & $\mathbf{\square}$ & & $\mathbf{\square}$ & $\mathbf{\square}$ & $\mathbf{\square}$ & \\
\hline Actinomycetales & & & & & & & & \\
\hline Aeromicrobium & & & & & & & & \\
\hline Arcanobacterium & $\mathbf{\square}$ & & & & & & & \\
\hline Actinobacteria & & & & & & & & \\
\hline Bordetella & $\mathbf{\square}$ & & & & & & & \\
\hline Caulobacter & & $\mathbf{\square}$ & $\mathbf{\square}$ & & $\mathbf{a}$ & & & $\mathbf{\square}$ \\
\hline Cellulomonas & $\mathbf{\square}$ & & & & & $\mathbf{\square}$ & & \\
\hline Cryobacterium & & & & & & & & \\
\hline Flavobacterium & $\mathbf{\square}$ & $\mathbf{\square}$ & $\mathbf{\square}$ & $\mathbf{\square}$ & $\mathbf{\square}$ & & $\mathbf{\square}$ & $\mathbf{\square}$ \\
\hline Frigoribacterium & & & & & & & & \\
\hline Janthinobacterium & 口 & & & & & & $\boldsymbol{\square}$ & \\
\hline Micrococcus & $\mathbf{\square}$ & $\mathbf{\square}$ & $\mathbf{\square}$ & & & & $\mathbf{\square}$ & $\mathbf{\square}$ \\
\hline Polaromonas & & & & & & $\mathbf{\square}$ & & \\
\hline Polynucleobacter & & & & $\mathbf{\square}$ & & $\mathbf{\square}$ & & $\mathbf{\square}$ \\
\hline Pseudomonas & 口 & 口 & $\mathbf{\square}$ & & $\mathbf{\square}$ & & $\mathbf{\square}$ & $\boldsymbol{\square}$ \\
\hline Rhodobacter & $\mathbf{\square}$ & & & $\mathbf{\square}$ & & & & \\
\hline Rhodococcus & & & & & & & $\mathbf{\square}$ & \\
\hline Rhodoferax & & $\mathbf{\square}$ & & $\mathbf{\square}$ & & $\mathbf{\square}$ & & $\mathbf{\square}$ \\
\hline Sphingomonas & 口 & & & 口 & $\mathbf{\square}$ & & $\boldsymbol{\square}$ & $\boldsymbol{\square}$ \\
\hline Staphylococcus & $\mathbf{\square}$ & & & & & & & \\
\hline Stenotrophomonas & & & & & & & & \\
\hline Tsukamurella & & & & & & & & \\
\hline Variovorax & & 口 & & $\mathbf{\square}$ & $\mathbf{\square}$ & & $\mathbf{\square}$ & $\mathbf{\square}$ \\
\hline
\end{tabular}

species level, differences related to the specific environment do occur.

\section{Reduction in species richness}

Using the Simpson diversity index (Simpson, 1949), from $16 \mathrm{~S}$ rRNA gene sequences Heywood Lake has a lower bacterioplankton biodiversity at 0.92 than Sombre Lake at 0.94 . The probability of selecting a clone with a new sequence from a random sample was $10 \cdot 3 \%(1: 10)$ for Heywood Lake and $16 \cdot 0 \%(1: 6)$ for Sombre Lake.

\section{Increasing evenness}

Lindström \& Leskinen (2002) cite several investigations of bacterioplankton diversity in aquatic environments with 
results indicating that although the species richness of these communities is high, only a few taxa $(<20)$ dominate. In this study a larger number of dominant groups were detected than in the adjacent oligotrophic lakes, suggesting nutrient enrichment has led to greater evenness among dominant bacterioplankton. The use of FISH showed that the $\beta$-Proteobacteria was clearly the most abundant group, followed by the Cytophaga-Flavobacterium group, the $\gamma$ Proteobacteria and the $\alpha$-Proteobacteria at most depths studied (Fig. 4). The $\beta$-Proteobacteria, however, were not as large a component of the Heywood Lake bacterioplankton as found in the Moss and Sombre Lake bacterioplankton and at a number of depths the Cytophaga-Flavobacterium were either equally or more abundant. In proportion to the overall population size, the $\gamma$-Proteobacteria and the $\alpha$ Proteobacteria were also relatively more numerous, suggesting that the species evenness of Heywood Lake is higher than that of Moss or Sombre Lakes (Pearce, 2003; Pearce et al., 2003).

\section{Dominant bacterioplankton groups and methodology}

The complementary results from each of the different methods stressed the importance of a polyphasic approach. $16 \mathrm{~S}$ sequence analysis of two-thirds of the predicted diversity present suggested over $70 \%$ of the sequences detected were from $\beta$-Proteobacteria, $15 \%$ from $\alpha$-Proteobacteria and $11 \%$ from Actinobacteria. FAME analysis indicated that $80 \%$ of cultured isolates were Actinobacteria, but as this technique is culture-dependent, this may indicate the Actinobacteria are taken into culture more readily, suggesting that they might be more resistant to environmental changes or have wider environmental tolerance limits. FISH indicated a predominance of $\beta$-Proteobacteria, followed by Cytophaga-Flavobacterium, $\gamma$-Proteobacteria and $\alpha$ Proteobacteria (unfortunately we did not have access to an Actinobacteria-specific probe in the field), whilst over $50 \%$ of DGGE bands were Actinobacteria, $23 \%$ Bacteroidetes and $8 \% \beta$-Proteobacteria. Taken together, these results suggest that there is much greater biodiversity among the $\beta$ Proteobacteria, but that a small number of key Actinobacteria dominate the Heywood Lake bacterioplankton community.

\section{Shift in dominance with trophic status}

A key observation from this study was an apparent shift in dominance with trophic status. Moss Lake was dominated by the Proteobacteria (5/9 DGGE bands), Sombre Lake showed no clear dominance, with equal numbers of Proteobacteria, Bacteroidetes and Actinobacteria, whilst the Actinobacteria dominated in Heywood Lake (7/13 DGGE bands), indicating a potential shift in dominant groups from $\beta$-Proteobacteria to Actinobacteria with increasing nutrient enrichment. The Actinobacteria are widespread and abundant in several lake systems.

\section{Resistant groups}

In Heywood Lake, three of the dominant groups were found to be dominant in neighbouring oligotrophic systems, suggesting that there are indeed important freshwater groups, or alternatively that there is a species-specific resistance to environmental perturbation in the form of nutrient enrichment. This is supported by the observation that Heywood Lake has a diversity of bacterioplankton which differs markedly from its neighbours, but this diversity does include some of the genera found in the oligotrophic systems, thus suggesting that specific groups may have a wider tolerance to environmental change.

\section{Conclusion}

Changes in the utilization of catchments by marine mammals or other perturbations of nutrient supply are likely to result in significant changes in the nutrient status and bacterioplankton communities of Antarctic lake systems. Nutrient-enriched Heywood Lake has a high bacterioplankton population density, reduced species richness and increasing evenness. Less than half of the genera found were also present in neighbouring oligotrophic lakes, including three of the dominant groups. A comparison of the three lakes with different nutrient levels suggested an apparent shift in dominance with trophic status. Other key observations included the absence of dominant Cyanobacteria and the presence of marine bacteria. Overall, the bacterioplankton community of Heywood Lake was distinct and differed markedly from its more oligotrophic neighbours. This significant impact of nutrient enrichment on Heywood Lake bacterioplankton communities, therefore, suggests that low-temperature oligotrophic freshwater lake systems may have low resistance to environmental change.

\section{ACKNOWLEDGEMENTS}

This research was supported by the Natural Environment Research Council through the British Antarctic Survey as part of the Terrestrial and Freshwater Biodiversity Project within the Antarctic Biodiversity, Past, Present and Future ASGC Programme. We would particularly like to thank Matt Edworthy for assistance in the field and for chemical analyses, Mairi Nicolson for assistance with sequencing and the many base members involved in the fur seal surveys. FAME analysis was supported by the Natural Environment Research Council through the Centre for Ecology and Hydrology, Oxford. We would also like to thank Cynan Ellis-Evans, Alex Rogers and the reviewers for helpful comments on the manuscript.

\section{REFERENCES}

Altschul, S. F., Madden, T., Schäffer, A. A., Zhang, J., Zhang, Z. W., Miller, W. \& Lipman, D. J. (1997). Gapped BLAST and PSI-BLAST: a new generation of protein database search programs. Nucleic Acids Res 25, 3389-3402.

Andrade, D. S., Murphy, P. J. \& Giller, K. E. (2002). The diversity of Phaseolus-nodulating rhizobial populations is altered by liming of acid soils planted with Phaseolus vulgaris L. in Brazil. Appl Environ Microbiol 68, 4025-4034. 
Bell, E. M. \& Laybourn-Parry, J. (1999). The plankton community of a young, eutrophic, Antarctic saline lake. Polar Biol 22, 248-253.

Bester, M. N., Ryan, P. G. \& Dyer, B. M. (2003). Population numbers of fur seals at Prince Edward Island, Southern Ocean. Afr J Mar Sci 25, 549-554.

Butler, H. G. (1999a). Seasonal dynamics of the planktonic microbial community in a maritime Antarctic lake undergoing eutrophication. J Plankton Res 21, 2393-2419.

Butler, H. G. (1999b). Temporal plankton dynamics in a maritime Antarctic lake. Arch Hydrobiol 146, 311-339.

Butler, H. G., Edworthy, M. G. \& Ellis-Evans, J. C. (2000). Temporal plankton dynamics in an oligotrophic maritime Antarctic lake. Freshw Biol 43, 215-230.

Crump, B. C., Kling, G. W., Bahr, M. \& Hobbie, J. E. (2003). Bacterioplankton community shifts in an Arctic Lake correlate with seasonal changes in organic matter source. Appl Environ Microbiol 69, 2253-2268.

D'Elia, C. F., Steudler, P. A. \& Corwin, N. (1977). Determination of total nitrogen in aqueous samples using persulphate digestion. Limnol Oceanogr 22, 760-764.

Donner, G., Schwartz, K., Hoppe, H.-G. \& Muyzer, G. (1996). Profiling the succession of bacterial populations in pelagic chemoclines. Arch Hydrobiol Spec Issue Adv Limnol 48, 7-14.

Drancourt, M., Bollet, C., Carlioz, A., Martelin, R., Gayral, J. P. \& Raoult, D. (2000). 16S ribosomal DNA sequence analysis of a large collection of environmental and clinical unidentifiable bacterial isolates. J Clin Microbiol 38, 3623-3630.

Dunbar, J., Takala, S., Barns, S. M., Davis, J. A. \& Kuske, C. R. (1999). Levels of bacterial community diversity in four arid soils compared by cultivation and $16 \mathrm{~S}$ rRNA gene cloning. Appl Env Microbiol 65, 1662-1669.

Ellis-Evans, J. C. (1982). Seasonal microbial activity in Antarctic freshwater lake sediments. Polar Biol 1, 129-140.

Ellis-Evans, J. C. (1990). Evidence for change in the chemistry of maritime Antarctic Heywood Lake. In Antarctic Ecosystems, Ecological Change \& Conservation, pp. 77-82. Edited by K. R. Kerry \& G. Hempel. Berlin: Springer.

Finlay, B. J. \& Maberly, S. C. (2000). Microbial Diversity in Priest Pot: A Productive Pond in the English Lake District. Edited by D. W. Sutcliffe. Ambleside: Freshwater Biological Association.

Fogg, G. E. (1998). The Biology of Polar Habitats. Oxford: Oxford University Press.

Glöckner, F. O., Zaichikov, E., Belkova, N., Denissova, L., Pernthaler, J., Pernthaler, A. \& Amann, R. (2000). Comparative 16S rRNA analysis of lake bacterioplankton reveals globally distributed phylogenetic clusters including an abundant group of Actinobacteria. Appl Environ Microbiol 66, 5053-5065.

Good, I. J. (1953). On the population frequencies of species and the estimation of population parameters. Biometrika 40, 237-264.

Hahn, M. W. (2003). Isolation of novel ultramicrobacteria classified as Actinobacteria from five freshwater habitats in Europe and Asia. Appl Environ Microbiol 69, 1442-1451.

Hawes, I. (1990). Eutrophication and vegetation development in maritime Antarctic lakes. In Antarctic Ecosystems, Ecological Change \& Conservation, pp. 83-90. Edited by K. R. Kerry \& G. Hempel. Berlin: Springer.

Heywood, R. B., Dartnall, H. J. G. \& Priddle, J. (1980). Characteristics and classification of the lakes of Signy Island, South Orkney Islands, Antarctica. Freshw Biol 10, 47-59.

Hiorns, W. D., Methé, B. A., Nierzwicki-Bauer, S. A. \& Zehr, J. P. (1997). Bacterial diversity in Adirondack mountain lakes as revealed by $16 \mathrm{~S}$ rRNA gene sequences. Appl Environ Microbiol 63, 2957-2960.

Irgens, R. L., Gosink, J. J. \& Staley, J. T. (1996). Polaromonas vacuolata gen. nov., sp. nov. a psychrophilic, marine, gas vacuolated bacterium from Antarctica. Int J Syst Bacteriol 46, 822-826.

Izaguirre, I., Mataloni, G., Allende, L. \& Vinocur, A. (2001). Summer fluctuations of microbial planktonic communities in a eutrophic lake - Cierva Point, Antarctica. J Plankton Res 23, 1095-1109.

Jones, V. J., Hodgson, D. A. \& Chepstow-Lusty, A. (2000). Palaeolimnological evidence for marked Holocene environmental changes on Signy Island, Antarctica. The Holocene 10, 43-60.

Kirchman, D. L. (2002). The ecology of Cytophaga-Flavobacterium in aquatic environments. FEMS Microbiol Ecol 39, 91-100.

Korsunov, V. M., Namsaraev, B. B., Gonchikov, G. G., Kozireva, L. P., Zakiyan, S. M. \& Zemskaya, T. I. (2003). Phylogenetic diversity of extremophiles in Baikal region: ecological and biotechnological aspects. http://www.bionet.nsc.ru/misc/ecopro/eng/1_12.html (accessed 8 May 2003).

Laybourn-Parry, J., Ellis-Evans, J. C. \& Butler, H. (1996). Microbial dynamics during the summer ice-loss phase in maritime Antarctic lakes. J Plankton Res 18, 495-511.

Lindström, E. S. (2000). Bacterioplankton community composition in five lakes differing in trophic status and humic content. Microb Ecol 40, 104-113.

Lindström, E. S. \& Leskinen, E. (2002). Do neighbouring lakes share common taxa of bacterioplankton? Comparison of $16 \mathrm{~S}$ rDNA fingerprints and sequences from three geographic regions. Microbial Ecol 44, 1-9.

Mackereth, F. J. H., Heron, J. \& Talling, J. F. (1989). Water Analysis: Some Revised Methods for Limnologists. Ambleside: Freshwater Biological Association.

Muyzer, G., de Waal, E. C. \& Uitterlinden, A. G. (1993). Profiling of complex microbial populations by denaturing gradient gel electrophoresis analysis of polymerase chain reaction-amplified genes coding for 16S rRNA. Appl Environ Microbiol 59, 695-700.

Noon, P. E., Leng, M. J., Arrowsmith, C., Edworthy, M. G. \& Strachan, R. J. (2002). Seasonal observations of stable isotope variations in a valley catchment, Signy Island, South Orkney Islands. Antarctic Sci 14, 333-342.

Pearce, D. A. (2000). A rapid, sensitive method for monitoring bacterioplankton community dynamics, applied to Antarctic freshwater lakes. Polar Biol 23, 352-356.

Pearce, D. A. (2003). Bacterioplankton community structure in a maritime Antarctic oligotrophic lake during a period of holomixis, as determined by denaturing gradient gel electrophoresis (DGGE) and fluorescence in situ hybridisation (FISH). Microb Ecol 46, 92-105.

Pearce, D. A. (2005). The structure and stability of the bacterioplankton community in Antarctic freshwater lakes, subject to extremely rapid environmental change. FEMS Microb Ecol 53, 61-72. Pearce, D. A., van der Gast, C., Lawley, B. \& Ellis-Evans, J. C. (2003). Bacterioplankton community diversity in a maritime Antarctic lake, as determined by culture dependent and culture independent techniques. FEMS Microbiol Ecol 45, 59-70.

Pinhassi, J., Zweifel, U. L. \& Hagström, A. (1997). Dominant marine bacterioplankton species found among colony-forming bacteria. Appl Environ Microbiol 63, 3359-3366.

Porter, K. G. \& Feig, Y. S. (1980). The use of DAPI for identifying and counting aquatic microflora. Limnol Oceanogr 25, 943-948.

Quayle, W. C., Peck, L. S., Peat, H., Ellis-Evans, J. C. \& Harrigan, P. R. (2002). Extreme responses to climate change in Antarctic lakes. Science 295, 645. 
Reynolds, C. S., Huszar, V., Kruk, C., Naselli-Flores, L. \& Melo, S. (2002). Towards a functional classification of the freshwater phytoplankton. J Plankton Res 24, 417-428.

Simpson, E. H. (1949). Measurement of diversity. Nature 163, 688. Smith, R. I. L. (1997). Impact of an increasing fur seal population on Antarctic plant communities, resilience and recovery. In Antarctic communities: Species, Structure \& Survival. Edited by B. Battaglia, J. Valencia \& D. W. H. Walton. Cambridge: Cambridge University Press.

Smith, V. H. (1983). Low nitrogen to phosphorus ratios favour dominance by blue-green algae in lake phytoplankton. Science 221, 669-671.

Smith, V. H. (1990). Nitrogen, phosphorus and nitrogen fixation in lacustrine and estuarine ecosystems. Limnol Oceanogr 35, 1852-1859.

Stockner, J. G. (1988). Phototrophic picoplankton: an overview from marine and freshwater ecosystems. Limnol Oceanogr 33, 765-775.

Stockner, J. G., Callieri, C. \& Cronberg, G. (2000). Picoplankton and other non-bloom-forming Cyanobacteria in lakes. In the Ecology of Cyanobacteria, pp. 195-231. B. A. Whitton \& M. Potts. The Netherlands: Kluwer.

Thompson, I. P., Bailey, M. J., Ellis, R. J. \& Purdy, K. J. (1993). Subgrouping of bacterial populations by cellular fatty acid composition. FEMS Microbiol Ecol 102, 75-84.

Trusova, M. Y. \& Gladyshev, M. I. (2002). Phylogenetic diversity of winter bacterioplankton of eutrophic Siberian reservoirs as revealed by $16 \mathrm{~S}$ rRNA gene sequences. Microb Ecol 44, 252-259.

Unrein, F. \& Vinocur, A. (1999). Phytoplankton structure and dynamics in a turbid Antarctic lake (Potter Peninsula, King George Island). Polar Biol 22, 93-101.
Urbach, E., Vergin, K. L., Young, L., Morse, A., Larson, G. L. \& Giovannoni, S. J. (2001). Unusual bacterioplankton community structure in ultra-oligotrophic Crater Lake. Limnol Oceanogr 46, 557-572.

van der Gast, C. J., Knowles, C. J., Wright, M. A. \& Thompson, I. P. (2001). Identification and characterisation of bacterial populations of an in-use metal-working fluid by phenotypic and genotypic methodology. Int Biodeter Biodegr 47, 113-123.

Vincent, W. F., Bowman, J. P., Rankin, L. M. \& McMeekin, T. A. (2000). Phylogenetic diversity of picocyanobacteria in Arctic and Antarctic ecosystems. In Microbial Biosystems: New Frontiers. Proceedings of the 8th International Symposium on Microbial Ecology, pp. 317-322. Edited by C. R. Bell, M. Brylinsky \& P. Johnson-Green. Halifax, Canada: Atlantic Canada Society for Microbial Ecology.

Welschmeyer, N. A. (1994). Fluorimetric analysis of chlorophyll- $a$ in the presence of chlorophyll- $b$ and pheopigments. Limnol Oceanogr 39, 1985-1992.

Yannarell, A. C., Kent, A. D., Lauster, G. H., Kratz, T. K. \& Triplett, E. W. (2003). Temporal patterns in bacterioplankton communities in three temperate lakes of different trophic status. Microb Ecol 46, 391-405.

Zhu, F., Wang, S. \& Zhou, P. J. (2003). Flavobacterium xinjiangense, sp. nov. and Flavobacterium omnivorum sp. nov., novel psychrophiles from the China No.1 glacier. Int J Syst Evol Microbiol 53, 853-857.

Zwart, G., Crump, B. C., Kamst-Agterveld, M. P., Hagen, F. \& Han, S.-K. (2002). Typical freshwater bacteria: an analysis of available $16 \mathrm{~S}$ rRNA gene sequences from plankton of lakes and rivers. Aquat Microb Ecol 28, 141-155. 